\title{
The Role of Cadherin in the Generation of Multinucleated Osteoclasts from Mononuclear Precursors in Murine Marrow
}

\author{
Gabriel Mbalaviele, Hong Chen, ${ }^{*}$ Brendan F. Boyce, * Gregory R. Mundy, and Toshiyuki Yoneda \\ University of Texas Health Science Center at San Antonio, Department of Medicine, Division of Endocrinology and Metabolism \\ and *Department of Pathology, San Antonio, Texas 78284
}

\begin{abstract}
A critical step in bone resorption is the fusion of mononuclear osteoclast precursors to form multinucleated osteoclasts. However, little is known of the molecular mechanisms that are responsible for this important process. Since the expression of proteins in the cadherin family of homophilic calcium-dependent cell adhesion molecules is involved in the fusion process for certain other cells, we examined their role in osteoclast formation. Immunohistochemical examination of human and mouse bone using monoclonal antibodies to human and mouse E-cadherin clearly demonstrated positive staining in osteoclasts. $\mathbf{N}$ - and $\mathbf{P}$-cadherin were not detected. In cultures of murine marrow mononuclear cells in which osteoclasts form by cell fusion, E-cadherin expression determined by Western blotting reached the highest levels as fusion was taking place. Expression of E-cadherin gene fragment was also detected in the marrow cultures by polymerase chain reaction. To study the functional role of $E$-cadherin expression in osteoclastic differentiation, neutralizing monoclonal antibodies were examined for their effects on osteoclast formation. The antibodies decreased the number of tartrate-resistant acid phosphatase (a marker of murine osteoclast)-positive multinucleated cell (TRAP-positive MNC) by inhibiting the fusion of mononuclear osteoclast precursors, but not proliferation of these cells or their attachment to plastic dish surfaces. This inhibitory effect was reversible. Furthermore, synthetic peptides containing the cell adhesion recognition sequence of cadherins also decreased TRAP-positive MNC formation. The antibodies and peptides inhibited not only osteoclast formation but also bone resorption. Antibodies to other types of cadherins and control rat IgG had no effects in these culture systems. Our findings suggest that $E$-cadherin expression may be involved in fusion (differentiation) of hemopoietic osteoclast precursors into mature multinucleated osteoclasts. ( $J$. Clin. Invest. 1995. 95:2757-2765.) Key words: cell-cell adhesion - homophilic - fusion - polymerase chain reaction - bone resorption
\end{abstract}

Address correspondence to Toshiyuki Yoneda, Dept. of Medicine/Endocrinology, University of Texas Health Science Center, 7703 Floyd Curl Dr., San Antonio, TX 78284-7877. Phone: 210-567-4900; FAX: 210-567-6693. 1995.

Received for publication 9 May 1994 and in revised form 2 February

J. Clin. Invest.

(c) The American Society for Clinical Investigation, Inc.

0021-9738/95/06/2757/09 \$2.00

Volume 95, June 1995, 2757-2765

\section{Introduction}

Osteoclasts are multinucleated bone-resorbing cells that are formed as a consequence of the differentiation of hematopoietic mononuclear progenitor cells. During differentiation, the mononuclear osteoclast precursors fuse to form syncytia of boneresorbing multinucleated osteoclasts under the influence of relatively specific mediators such as 1,25 dihydroxyvitamin $D_{3}$ $\left(1,25 D_{3}\right)^{1}(1)$. This fusion process seems likely to be initiated by intimate cell-cell interactions which occur between the mononuclear osteoclast precursors. However, the molecular mechanisms responsible for this fusion process are totally unclear at the present time. In other systems in which cell fusion plays a crucial role in cellular differentiation such as trophoblast formation in the placenta $(2,3)$ and myotube formation from myoblasts $(4,5)$, it has been shown that the fusion process may require expression of cadherins, which are calcium-dependent cell-cell adhesion molecules.

Cadherins are families of transmembrane glycoproteins which are calcium-dependent cell-cell adhesion molecules that bind to one another by means of homophilic interactions (6). Because of their homophilic properties in cell-cell adhesion and expression patterns during embryonic development, cadherins have been implicated in the control of embryogenesis and morphogenesis. In addition, the role of cadherins in cellular differentiation in a wide variety of tissues has recently been described (7).

In the present study we examined the role of cadherin families in the formation of osteoclasts. We used cultures of mouse marrow mononuclear cells in which osteoclast-like cells are formed in the presence of $1,25 \mathrm{D}_{3}$ due to the fusion of the hematopoietic osteoclast precursors. We have found that one of the cadherin family members, E-cadherin, is present in osteoclasts, and that inhibition of E-cadherin function by antibodies and antagonistic synthetic peptides prevent the fusion of osteoclast precursors to form multinucleated bone-resorbing osteoclasts. These findings suggest an important role of E-cadherin in the differentiation of hematopoietic precursor cells into osteoclasts.

\section{Methods}

Antibodies. Neutralizing monoclonal antibody to mouse E-cadherin (ECCD-1), non-neutralizing monoclonal antibody to mouse E-cadhe-

1. Abbreviations used in this paper: $\alpha \mathrm{MEM}$, alpha minimal essential medium; Cam, cell adhesion molecules; $1,25 \mathrm{D}_{3}, 1,25$ dihydroxyvitamin $\mathrm{D}_{3}$; BGJb medium, Fitton-Jackson modified Biggers, Gwatkin, Judah medium; DECMA-1, monoclonal antibody to mouse E-cadherin; Ecadherin, epithelial cadherin; ECCD-1, neutralizing monoclonal antibody to mouse E-cadherin; ECCD-2, non-neutralizing monoclonal antibody to mouse E-cadherin; HAV, histidine-alanine-valine recognition sequence motif; HECD-1, neutralizing monoclonal antibody to human E-cadherin; HRP, horse radish peroxidase; $\mathrm{N}$-cadherin, neural cadherin; P-cadherin, placental cadherin; PCD-1, neutralizing monoclonal antibody to mouse P-cadherin; PTH-rP, parathyroid hormone-related pep- 
rin (ECCD-2), neutralizing monoclonal antibody to human E-cadherin (HECD-1), and neutralizing monoclonal antibody to mouse P-cadherin (PCD-1) were obtained from Takara Biochemical Inc. (Berkeley, CA). Nose et al. (8) have reported that the ECCD-1 recognizes the site around nonconserved residue 16 (glutamic acid) of mouse E-cadherin and the PCD-1 around nonconserved residue 31 (glycine) of mouse P-cadherin. Monoclonal antibody to mouse E-cadherin (DECMA-1, which also cross-reacts with human E-cadherin) were a generous gift of Dr. R. Kemler (Max-Planck Institut für Immunobiologie, Freiburg, Germany) (9). Neutralizing monoclonal antibody to chicken $\mathrm{N}$-cadherin (anti-A-CAM) and control rat IgG were purchased from Sigma Immunochemicals (St. Louis, MO). Biotin-conjugated rabbit anti-mouse IgG, biotin-conjugated rabbit anti-rat IgG, and streptavidin biotin-conjugated horse radish peroxidase (HRP) were obtained from Dako (Carpenteria, CA.).

Mouse marrow cell cultures. Mouse marrow cultures were carried out as described (10). Bone marrow cells were collected from femora and tibiae of C57BL mice (male, 4-6-wk-old; Harlan Industries, Houston TX), washed twice with serum-free alpha minimum essential medium ( $\alpha$ MEM; Hazleton Biologics Inc., Lenexa, KS), plated in 48-well plates (Falcon; Becton Dickinson Labware, Lincoln Park, NJ) at a final density of $1.3 \times 10^{6}$ cells $/ \mathrm{cm}^{2}$, and cultured in $\alpha \mathrm{MEM}$ supplemented with $10 \%$ FCS (Hyclone Laboratories, Logan, UT), no antibiotics and $10 \mathrm{nM} 1,25 \mathrm{D}_{3}$ (Biomol Research Laboratory Inc., Plymouth Meeting, PA) for $6 \mathrm{~d}$ at $37^{\circ} \mathrm{C}$ in a humidified atmosphere of $5 \% \mathrm{CO}_{2}$ in air. The cells were fed every $2 \mathrm{~d}$, unless otherwise specified, with fresh $\alpha \mathrm{MEM}$ containing $10 \%$ FCS and $10 \mathrm{nM} 1,25 \mathrm{D}_{3}$.

At the end of the culture, the cells were washed with PBS, fixed in $60 \%$ acetone in citrate buffer ( $\mathrm{pH} \mathrm{5.4)}$ ) for $30 \mathrm{~s}$, air dried, and stained for tartrate-resistant acid phosphatase (TRAP), which is a widely accepted cytochemical marker of murine osteoclasts (11), using a commercially available kit (Sigma). Stained cultures were examined under light microscopy at a magnification of 200. TRAP-positive (red-staining) multinucleated (three or more nuclei) cells (TRAP $(+) \mathrm{MNC}$ ) in each well were counted by manually scanning across the entire well in a systematic fashion.

Isolation of neonatal mouse osteoclasts. Osteoclasts obtained for these experiments were prepared from the femora and tibiae of newborn mice according to techniques previously described $(12,13)$. The bones of each mouse were curetted with a scalpel blade into $1 \mathrm{ml}$ of medium and vigorously agitated with a pipette. The supernatants were added to slices of sperm whale dentine. The cells were then incubated for 15 min at $37^{\circ} \mathrm{C}$. Dentine slices were then removed, washed, and placed in separate wells containing $100 \mu \mathrm{l}$ of $\alpha \mathrm{MEM}$ supplemented with $10 \%$ FCS.

Assay for resorption pit formation by TRAP $(+) M N C$ and isolated mature mouse osteoclasts. Resorption pit formation by TRAP $(+) \mathrm{MNC}$ or isolated mature mouse osteoclasts on calcified matrix was determined according to the technique previously described $(10,14)$, which was originally developed by Boyde et al. (15). Sperm whale dentine $(0.25$ $\times 7 \times 7 \mathrm{~mm}$ ) was prepared using a Buehler low speed diamond saw (Buehler, Lake Bluff, IL) followed by sonication (15 $\mathrm{min}$ ) in several changes of distilled water. Slices were smoothened between two glass plates and sterilized under UV light for $4 \mathrm{~d}$. Before all experiments, slices were incubated in $\alpha$ MEM supplemented with 5\% FCS and $1 \%$ penicillin-streptomycin solution (GIBCO BRL, Gaithersburg, MD) for at least $48 \mathrm{~h}$. Cultures were performed in humidified air $\left(10 \% \mathrm{CO}_{2}\right)$ at $37^{\circ} \mathrm{C}$ ( 1 slice/well). A single experiment used 16-20 slices, with a minimum of 3-4 slices/treatment. Experiments were repeated at least 3-4 times.

Mouse marrow cells were isolated, plated at a density of $1 \times 10^{6}$ cells/slice and cultured in the presence of $10 \mathrm{nM} 1,25 \mathrm{D}_{3}$ as described above. After $6 \mathrm{~d}$, the cultures were stained for TRAP activity and numbers of TRAP $(+) \mathrm{MNC}$ formed were counted. The cells were then removed from the dentine surface by sonication in $0.1 \mathrm{~N} \mathrm{NaOH}$ and

tides; TRAP, tartrate-resistant acid phosphatase; TRAP(+)MNC, tartrate-resistant acid phosphatase-positive multinucleated cell. resorption pits were stained with $0.1 \%(\mathrm{wt} / \mathrm{vol})$ toluidine blue (Sigma) solution. Pits were counted using light microscopy, and the plan area of matrix resorbed was quantitated using a computer-assisted JAVA image analysis system (Jandel Scientific, Corte Madera, CA). Data were analyzed by pattern analysis of variance (13).

Isolated mature mouse osteoclasts were cultured in the presence of $50 \mathrm{ng} / \mathrm{ml}$ synthetic (1-34) human parathyroid hormone-related peptides (PTH-rP; Peninsula Laboratories Inc., Belmont, CA) on dentine slices for $24 \mathrm{~h}$, stained for TRAP, counted their cell number, removed from dentine surface, and assessed for their resorption pit formation as described above.

Assay for bone resorption in organ cultures of neonatal mouse calvariae. The bone resorption assay that was utilized for these experiments has been described in detail previously (16). Pregnant ICR Swiss mice (Harlan Sprague Dawley, Inc., Indianapolis, IL) at $17 \mathrm{~d}$ of gestations were injected subcutaneously with $25 \mu \mathrm{Ci}^{45} \mathrm{Ca}$ (ICN Radiochemicals, Costa Mesa, CA). The frontal and parietal bones were removed by microdissection and split along the sagittal suture from 6-d-old neonates. Half-calvariae were cultured with $0.5 \mathrm{ml}$ of Fitton-Jackson modified Biggers, Gwatkin, and Judah (BGJb) medium (Sigma) supplemented with $0.1 \%$ BSA. Following a 24-h period of culture with BGJb medium to allow for exchange of loosely complexed ${ }^{45} \mathrm{Ca}$ with stable calcium in the medium, the bones were further incubated in test media for 72 h. Four half-calvariae were used in each experimental group. Bone resorption was determined by measuring the percent of total radioactivity released from the bones during the culture period with the test substances.

Immunohistochemistry. Mouse long bones and human bone obtained at biopsy were fixed in $10 \%$ buffered formalin for up to $48 \mathrm{~h}$, decalcified in $14 \%$ EDTA for 2-3 wk, and embedded in paraffin. 1-2- $\mu \mathrm{m}$ sections were incubated with $3 \% \mathrm{H}_{2} \mathrm{O}_{2}$ in PBS to quench endogenous peroxidase and then incubated with $10 \%$ ovalbumin for 30 min to block nonspecific binding. Thereafter, the sections were incubated with one of the following antibodies, DECMA-1, HECD-1, anti-A-CAM, or PCD1 for $3 \mathrm{~h}$, followed by biotin-conjugated secondary antibodies and streptavidin-biotin conjugated HRP complex (Dako) for $40 \mathrm{~min}$ each. Sections were then incubated with $0.05 \mathrm{M}$ Tris buffer ( $\mathrm{pH}$ 7.6) containing $0.025 \% 3.3^{\prime}$-diaminobenzidine tetrahydrochloride (Sigma) and $0.003 \%$ $\mathrm{H}_{2} \mathrm{O}_{2}$ (Sigma) for 20 min and counterstained with $0.5 \%$ methyl green (Sigma), using standard techniques (16). All incubations were carried out at room temperature.

Immunofluorescent staining of E-cadherin. Mouse marrow cells cultured in the presence of $10 \mathrm{nM} 1,25 \mathrm{D}_{3}$ were fixed with a fresh solution of $3.7 \%$ (wt/vol) formaldehyde in PBS at room temperature for 30 min, incubated with the primary antibodies, DECMA-1 at 1:200 dilution in PBS containing $1 \%$ rabbit serum at $37^{\circ} \mathrm{C}$ for $1.5 \mathrm{~h}$ in humidified atmosphere, washed three times with PBS and incubated with 1:80 diluted affinity-purified rabbit anti-rat IgG conjugated with fluorescein5-isothiocyanate (Sigma). After washing with PBS, cells were mounted in PBS-glycerol solution (1:1) and examined under a fluorescence microscope (Nikon Inc., Instrument Division, Garden City, NY).

Immunoprecipitation and immunoblotting. Mouse marrow cells cultured for certain period of times in the presence of $10 \mathrm{nM} 1,25 \mathrm{D}_{3}$ were lysed in NP-40 lysis buffer ( $20 \mathrm{mM}$ Tris, pH $8.0,2 \mathrm{mM} \mathrm{CaCl}, 150$ $\mathrm{mM} \mathrm{NaCl}, 1 \% \mathrm{NP}-40$ ) containing protease inhibitors ( $20 \mathrm{mM}$ leupeptin, $1 \mathrm{mM}$ PMSF, $1 \%$ aprotinin) at $4^{\circ} \mathrm{C}$, centrifuged at $10,000 \mathrm{~g}$ for $10 \mathrm{~min}$ at $4^{\circ} \mathrm{C}$, and determined for protein amounts using the Bio-Rad DC protein assay (Bio Rad Labs., Hercules, CA). The lysates were incubated with $10 \mu \mathrm{g}$ DECMA-1 mAbs for $2 \mathrm{~h}$ at $4^{\circ} \mathrm{C}$ and then with 2 $\mu \mathrm{g}$ rabbit anti-rat IgG as an intermediate reagent for $2 \mathrm{~h}$ at $4^{\circ} \mathrm{C}$. The immunocomplexes were precipitated with $100 \mu \mathrm{l}$ Protein $\mathrm{G}$ (Boehringer Mannheim Corp., Indianapolis, IN) for $2 \mathrm{~h}$ at $4^{\circ} \mathrm{C}$.

The immunoprecipitates were boiled for $5 \mathrm{~min}$, separated on $7.5 \%$ sodium dodesylsulfate polyacrylamide gel electrophoresis and transferred onto polyvinyldine difluoride membranes (Immobilon-P; Millipore Corp., Bedford, MA) in transblotting buffer containing $20 \mathrm{mM}$ Tris, $150 \mathrm{mM}$ glycine, and $20 \%$ methanol ( $\mathrm{pH} \mathrm{8.0)}$ ). The membranes were incubated with blocking buffer consisting of 5\% nonfat dry milk (Carnation Company, Los Angeles, CA) in $50 \mathrm{mM}$ Tris, $150 \mathrm{mM} \mathrm{NaCl}$, 

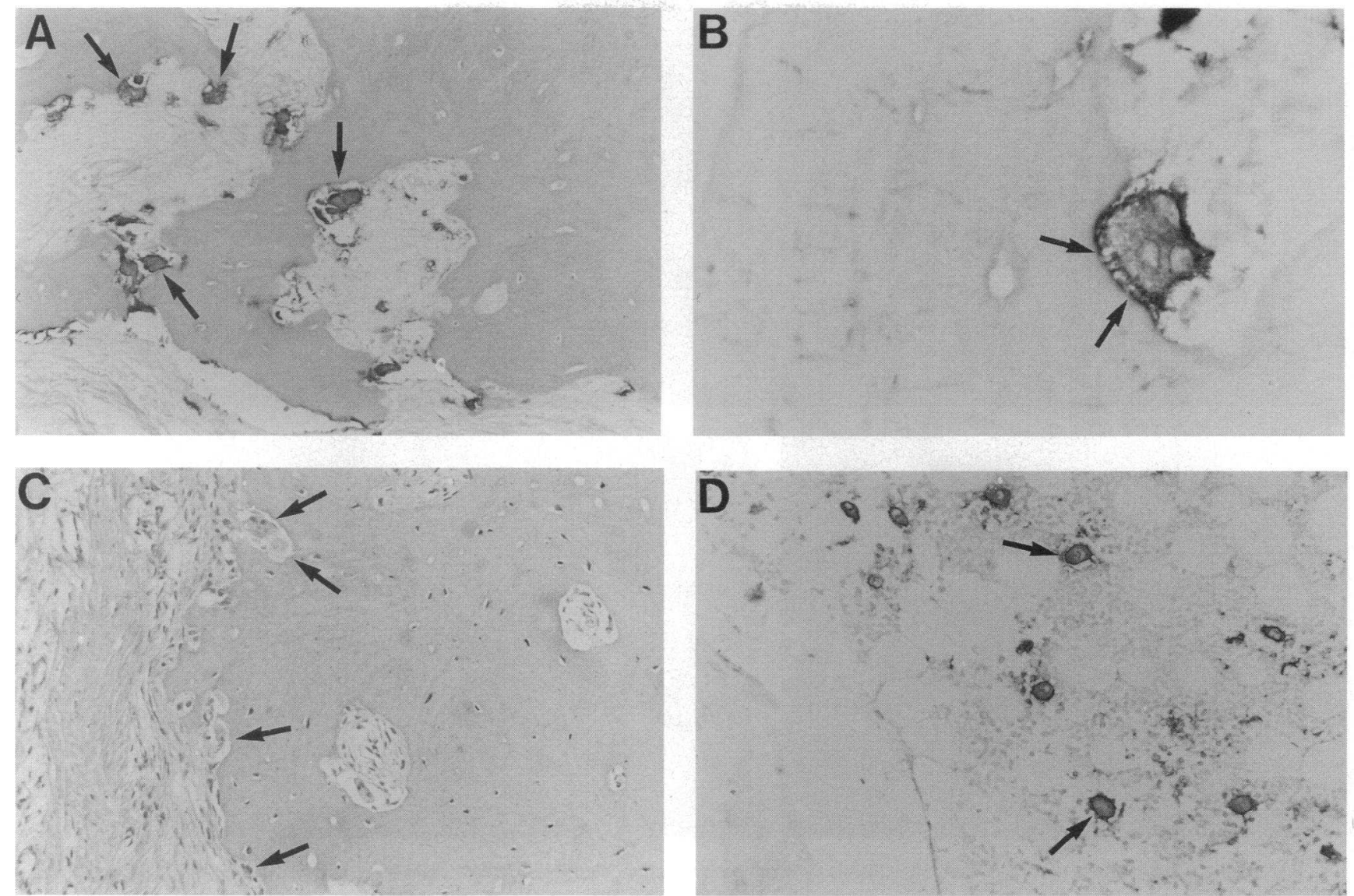

Figure 1. Cadherin expression in vivo in osteoclasts. Human bone sections were incubated with HECD-1, PCD-1, or anti-A-CAM as described in Methods. $(A)$ The multinucleated osteoclasts (arrows) on the endosteal resorbing bone surface show intense E-cadherin expression along their plasma membranes. $(B)$ Higher magnification shows intense expression of E-cadherin along the ruffled border membrane (arrows) at the interface between the osteoclast and the underlying bone. $(C)$ No expression of $\mathrm{N}$ - and P-cadherin (not shown) was found in osteoclasts (arrows). (D) Strong plasma membrane expression of E-cadherin was also demonstrated in megakaryocytes (arrows).

$10 \mathrm{mM} \mathrm{CaCl}_{2}, 0.05 \%$ Tween-20 (TBST) for $2 \mathrm{~h}$, and then with DECMA-1 mAbs (diluted $1 / 1,000$ in TBST) for $2 \mathrm{~h}$, washed three times with TBST, incubated with biotin-conjugated rabbit anti-rat IgG (Dako) (diluted $1 / 1500$ in TBST) for $1 \mathrm{~h}$. After being washed three times with TBST, the membranes were incubated with streptavidin biotinconjugated HRP (Dako) for $\mathbf{4 0}$ min, washed three times in TBST and stained with $0.05 \mathrm{M}$ Tris buffer ( $\mathrm{pH} 7.6)$ containing $0.025 \% 3,3^{\prime}$ diaminobenzidine tetrahydrochloride (Sigma) and $0.003 \% \mathrm{H}_{2} \mathrm{O}_{2}$ for 20 min. All incubations were carried out at room temperature.

$P C R$ and DNA sequencing. Polyadenylated RNA was isolated from 6-d cultures of mouse bone marrow cells in which TRAP $(+)$ MNC formed in the presence of $10 \mathrm{nM} 1,25 \mathrm{D}_{3}$ using the Micro-Fast Track ${ }^{\mathrm{TM}}$ mRNA system (Invitrogen, San Diego, CA). cDNAs were then synthesized from poly $(\mathrm{A})^{+}$RNA preparations using Moloney murine leukemia virus reverse transcriptase (Perkin-Elmer Cetus Instrs., Norwalk, CT). PCR was carried out according to the method described previously (18) using the cDNA as a template. Two degenerate oligonucleotides as PCR primers were designed based on two highly conserved regions in the cytoplasmic domain of mouse $\mathrm{N}$-cadherin (19) as described (18). After 35 reaction cycles, the reaction products were separated by agarose gel electrophoresis and DNA bands of $\sim 160 \mathrm{bp}$ in size were extracted. Taq DNA polymerase and the other reagents used in PCR were purchased from Promega (Madison, WI). The resultant DNAs were subcloned into $\mathrm{PCR}^{\mathrm{TM}} \mathrm{II}$ vector using the $\mathrm{TA}$ cloning ${ }^{\mathrm{TM}}$ kit (Invitrogen) for DNA sequencing.

Sequencing of DNAs was conducted according to the dideoxynucleotide chain termination method of Sanger et al (20) using DNA sequencing kit (Sequenase Version 2.0; United States Biochemical Corp., Cleveland, $\mathrm{OH}$ ).

Statistical analysis. All data were analyzed by ANOVA followed by a paired $t$ test.

\section{Results}

Cadherin expression in osteoclasts in human and mouse bones. Examination of sections of human bone incubated with the $\mathrm{mAb}$ HECD-1 and the mAb DECMA-1, respectively, demonstrated a strong signal for E-cadherin along the cell membrane of osteoclasts at resorbing bone surfaces (Fig. $1 \mathrm{~A}$ ) and a lighter signal within the cytoplasm of these cells. Similar expression was detected in sections of murine bone (data not shown). Furthermore, a strong signal was also detected along the ruffled border of osteoclasts (Fig. $1 \mathrm{~B}$ ). No signal was detected in osteoclasts incubated with anti-A-CAM or PCD-1 (Fig. $1 C$ ). A strong signal for E-cadherin was detected along the cell membrane of megakaryocytes in human bone marrow (Fig. 1 D).

E-cadherin expression in mouse marrow cultures. Based on the in vivo immunohistochemical data, we next examined Ecadherin expression in mouse marrow cultures in which TRAP $(+) \mathrm{MNC}$ form in the presence of $1,25 \mathrm{D}_{3}$. Immunofluorescent staining of the cultures at day 6 using DECMA-1 mAbs 

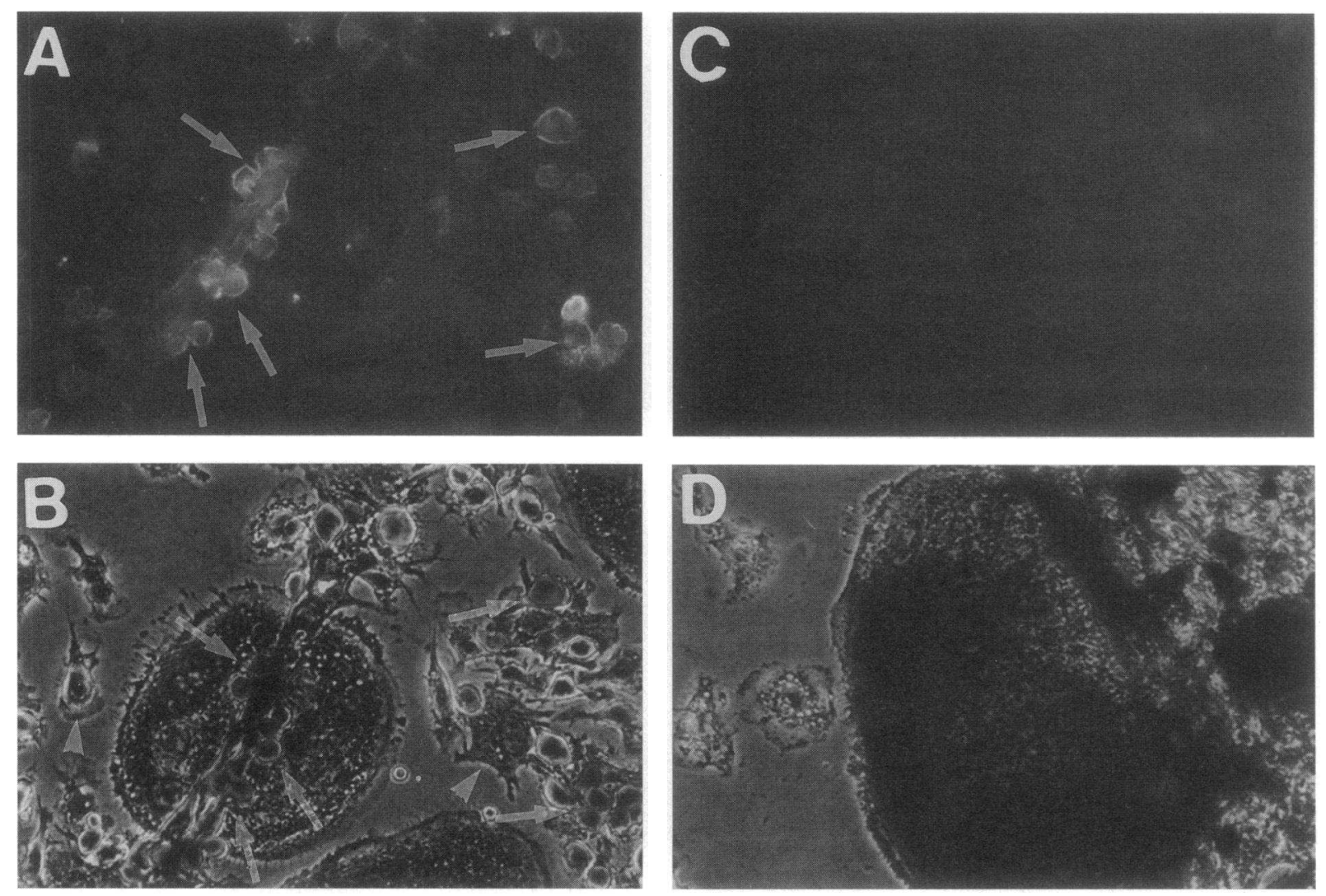

Figure 2. E-cadherin expression in mouse marrow cultures determined by immunostaining. Marrow cells were cultured in the presence of $10 \mathrm{nM}$ $1,25 \mathrm{D}_{3}$ for $4(A-D)$ and $6(E$ and $F)$ d, fixed, and stained with DECMA-1 antibodies for E-cadherin expression. The same cultures were then stained for TRAP positivity. TRAP $(+)$ mononuclear cells (arrows) exhibited strong E-cadherin expression when the fusion began to occur at day 4 of cultures $(A$ and $B)$. TRAP $(-)$ mononuclear cell (arrowhead) does not express E-cadherin. TRAP $(+)$ MNC incubated only with second antibodies show no staining $(C$ and $D)$. TRAP $(+)$ MNC formed at day 6 of cultures also demonstrate E-cadherin expression $(E$ and $F)$. $(A, C$, and $E$ ), immunofluorescent staining; $(B, D$, and $F)$, TRAP staining.

demonstrated strong E-cadherin expression in TRAP $(+)$ mononuclear cells (Fig. 2, $A$ and $B$ ) which were most likely osteoclast precursors that eventually fuse to form TRAP $(+)$ MNC. No staining was detected in TRAP $(-)$ mononuclear cells (Fig. 2 $B)$. E-cadherin expression was also observed on the cell membrane of TRAP(+)MNC (Fig. 2, $E$ and $F$ ). TRAP(+) mononuclear cells and TRAP $(+)$ MNC incubated without DECM-1 mAbs showed no staining (Fig. 2, $C$ and $D$ ).

As shown by Western blotting, E-cadherin expression in marrow cultures was time dependent and reached the highest levels at day 4 when TRAP $(+)$ mononuclear cells began to fuse and decreased at day 6 when the fusion was almost achieved (Fig. 3, top). Marrow cells cultured in the absence of $1,25 \mathrm{D}_{3}$ did not form TRAP $(+)$ mononuclear cells and TRAP (+)MNC and showed no detectable levels of E-cadherin expression by Western blotting and immunofluorescent (data not shown).

PCR amplification of reverse-transcribed mRNA from 6-d culture of $1,25 \mathrm{D}_{3}$-treated mouse marrow cells produce a DNA fragment at $163 \mathrm{bp}$ in size which had identical sequence to Ecadherin (Fig. 3, bottom).

Effects of the antibodies to various types of cadherins on $T R A P(+) M N C$ formation in marrow cultures. The expression of E-cadherin in osteoclasts in vivo and in TRAP $(+)$ mononuclear cells and TRAP $(+) \mathrm{MNC}$ in vitro led us to investigate whether E-cadherin plays a role in the formation of osteoclasts.
We first studied the effects of ECCD-1 on the formation of multinucleated osteoclast-like cells in mouse marrow cultures. In this culture system, TRAP $(+) \mathrm{MNC}$ with bone-resorbing activity are formed as a result of the sequential events of proliferation, differentiation and fusion of the hematopoietic mononuclear osteoclast precursors (21). ECCD-1 mAbs markedly decreased the formation of TRAP $(+) M N C$ (Fig. 4). We also examined whether other families of cadherins mediate the fusion of the osteoclast precursors by testing the effects of panels of the antibodies to other cadherins. PCD-1 and anti-A-CAM were ineffective (Fig. 4). This result is consistent with our in vivo immunohistochemistry data that osteoclasts in bone did not express P-cadherin and N-cadherin. Furthermore, ECCD-2 and HECD-1 showed no effects (Fig. 4). Rat IgG used as a control showed no significant inhibition of the formation of TRAP $(+)$ MNC. The inhibitory effect of ECCD-1 mAbs was dose dependent and maximum inhibition was obtained at a concentration of $10 \mu \mathrm{g} / \mathrm{ml}$ (data not shown). Other antibodies even at $10 \mu \mathrm{g} / \mathrm{ml}$ showed no effects (data not shown). These data demonstrate that mouse E-cadherin expression determines the capacity of osteoclast precursors to fuse to form multinucleated osteoclast-like cells in mouse marrow cell cultures.

Effects of ECCD-1 on adhesion to plastic dish surface, proliferation, and the fusion during TRAP(+)MNC formation in mouse marrow cultures. Although the experiments described above demonstrated that E-cadherin plays a role in osteoclast- 

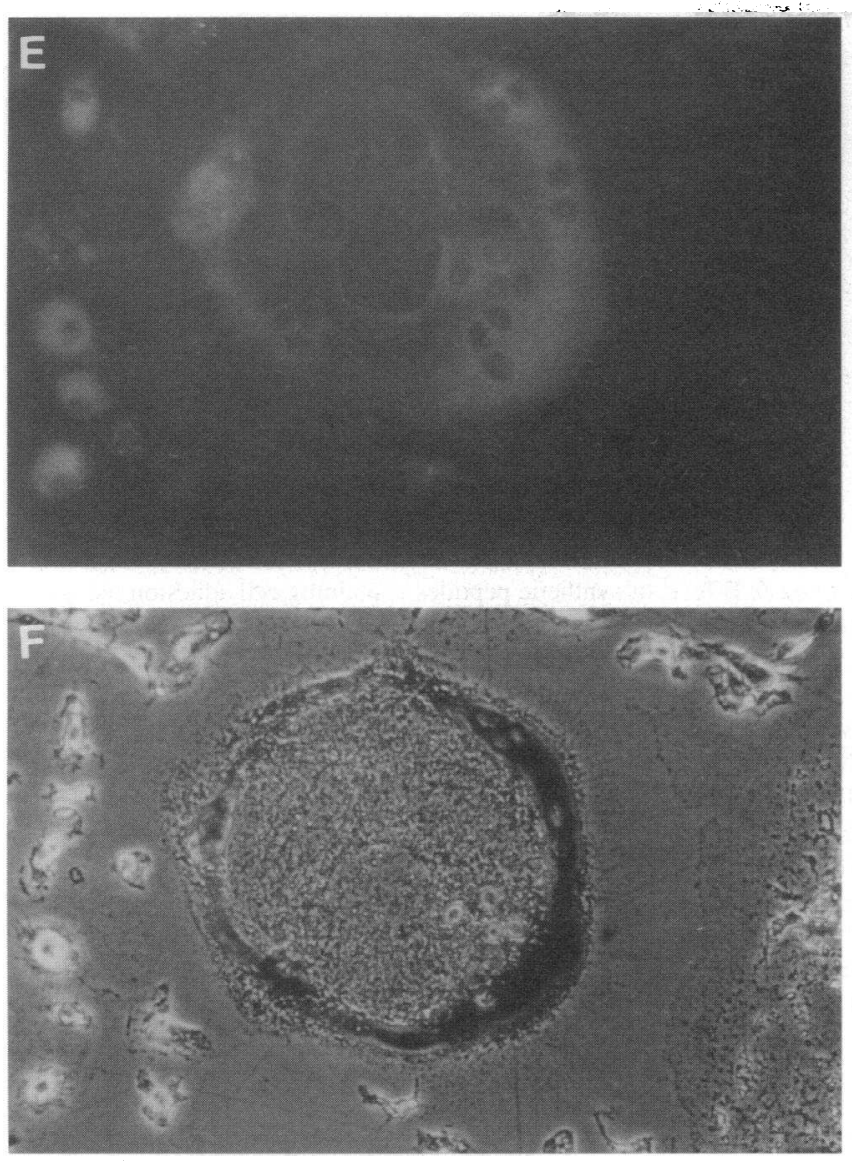

Figure 2 (Continued)

1

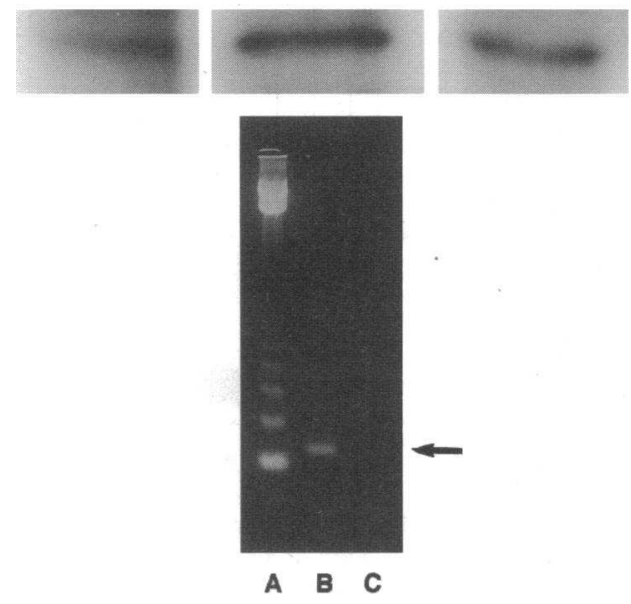

Figure 3. E-cadherin expression in mouse marrow cultures determined by immunoblotting (top) and PCR (bottom). (Top) Marrow cells were cultured in the presence of $10 \mathrm{nM} 1,25 \mathrm{D}_{3}$ for 2,4 , and $6 \mathrm{~d}$. At each time point cells were lysed and subjected to Western blotting. Lane 1 , 2-d culture; lane 2, 4-d culture; lane 3, 6-d culture. (Bottom)

Poly (A) ${ }^{+}$RNA was isolated from 6-d culture of murine marrow cells. $A$ PCR product at $163 \mathrm{bp}$ (arrow) in lane $B$ had $100 \%$ identical sequence to E-cadherin (not shown). Lane $A$, standard size marker; lane $C$, water.

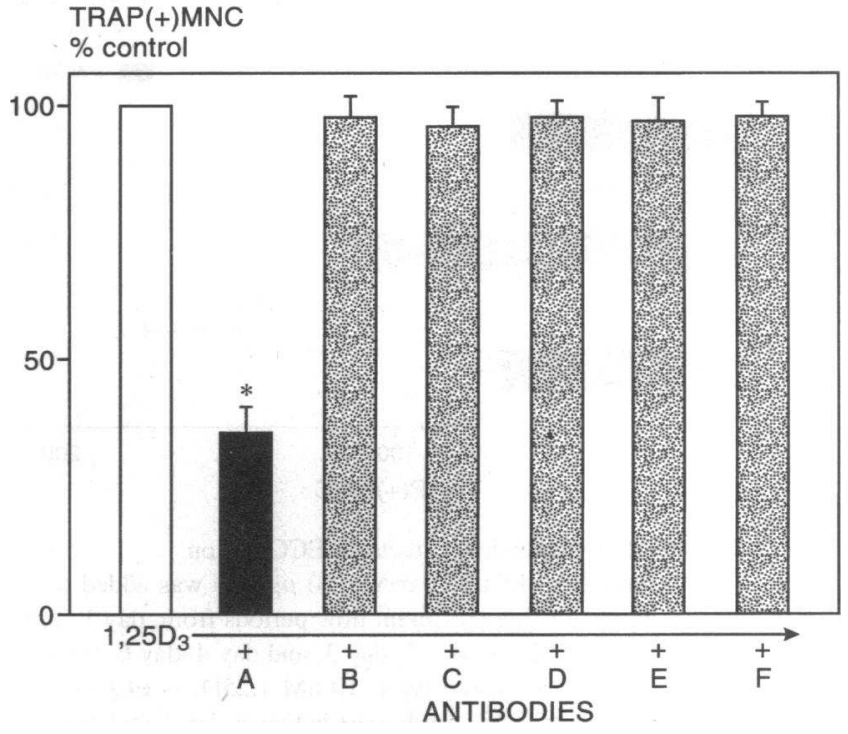

Figure 4. Effects of the antibodies to various types of cadherins on the formation of TRAP( +$)$ MNC. Mouse marrow cells were cultured with $10 \mathrm{nM} 1,25 \mathrm{D}_{3}$ in the presence of $1 \mu \mathrm{g} / \mathrm{ml}$ of neutralizing mAbs to mouse E-cadherin $(A), \mathrm{N}$-cadherin $(B), \mathrm{P}$-cadherin $(C)$, and human Ecadherin $(D)$ and non-neutralizing antibodies to mouse E-cadherin $(E)$ and control rat IgG $(F)$. The inhibition of TRAP $(+)$ MNC formation was observed in ECCD-1 mAb-treated cultures $(A)$ but not in antiA-CAM $(B)$, PCD-1 $(C)$, HECD-1-treated $(D)$, and ECCD-2 $(E)$ cultures. Results are the mean \pm SEM of two experiments with four determinations for each group. * Significantly different from the group treated with $1,25 \mathrm{D}_{3}$ alone $(P<0.01)$.

like cell formation, they did not show whether ECCD-1 mAbs decreased TRAP $(+)$ MNC formation by inhibiting adhesion to plastic dish surface, proliferation or fusion of the hematopoietic osteoclast precursors. We next examined the effects on TRAP(+)MNC formation of ECCD-1 mAbs which were added at different stages of marrow cultures.

The cultures were treated with ECCD-1 mAbs from: $(a)$ day 1 (the day of cell inoculation) to day $3 ;(b)$ day 4-6; (c) day $1-6$ in the presence of $10 \mathrm{nM} 1,25 \mathrm{D}_{3}$. Cells were stained for TRAP activity at day 6 of the culture. In this marrow culture system, attachment of the hematopoietic osteoclast precursors to plastic dish surfaces, with spreading and proliferation occurring between day 1 and day 3 and after this, fusion of TRAP mononuclear cells to form TRAP $(+)$ MNC starts, reaching a maximum at day 4 or 5. ECCD-1 mAbs showed no effects when present during the first 3 days of the culture (Fig. 5). By contrast, cultures treated with ECCD-1 mAbs during the last $3 \mathrm{~d}$ of the culture showed a marked decrease in $\operatorname{TRAP}(+) \mathrm{MNC}$ formation in the same manner as when the antibodies were present for the entire culture period. These results strongly suggest that E-cadherin plays an important role in the fusion of the hematopoietic osteoclast precursors to form multinucleated osteoclasts.

It should also be noted that the experiments showed that the ECCD-1 mAbs tested here did not have cytotoxic effects on bone marrow cells, since marrow cells which were treated with the antibodies for the first $3 \mathrm{~d}$ and without the antibodies for the next $3 \mathrm{~d}$ showed no decrease in TRAP $(+) \mathrm{MNC}$ formation after $6 \mathrm{~d}$ of culture.

Inhibition of TRAP $(+) M N C$ formation in marrow cultures by synthetic peptides containing cell adhesion recognition se- 


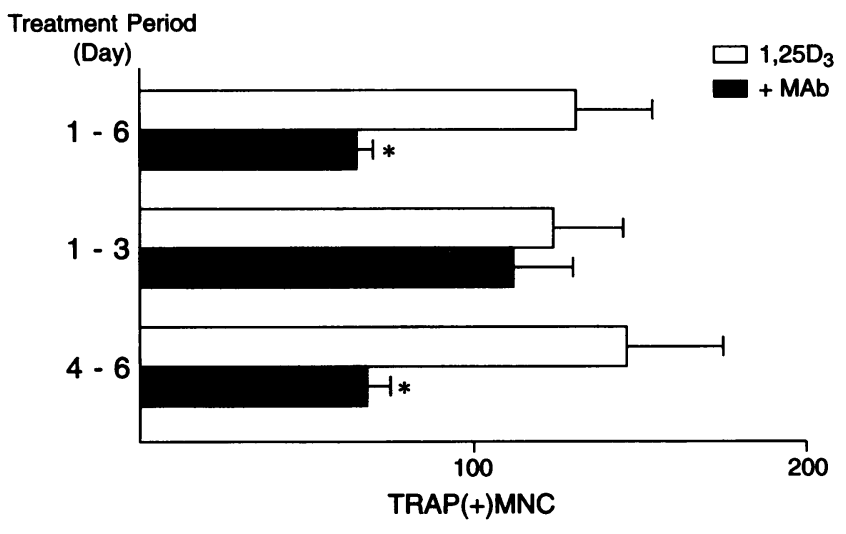

Figure 5. Culture stage-dependent effects of ECCD-1 on

TRAP (+)MNC formation. ECCD-1 mAb $(10 \mu \mathrm{g} / \mathrm{ml})$ was added to mouse marrow cultures for three different time periods from: day 1 (the day of cell inoculation) to day 6, day 1-day 3, and day 4-day 6. (Open

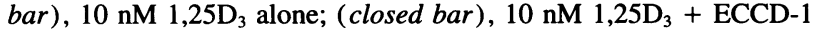
$\mathrm{mAb}$. In cultures treated with the antibodies between day 1 and day 3 , non-adherent cells were harvested at day 3 , washed in the culture medium without the antibodies twice and replated back to the same wells. Adherent cells that remained in the wells were also washed with the medium containing no antibodies. Cultures were then continued in the medium without the antibodies until day 6 . The other two groups (days 1-6 and 4-6) were also treated and cultured in the same manner. All cultures were stained for TRAP activity at day 6 of culture. Treatment of cultures with ECCD-1 mAb for $6 \mathrm{~d}$ markedly decreased TRAP(+)MNC number. There was no effect of ECCD-1 mAb during the first $3 \mathrm{~d}$ in which cell adhesion to the plastic dish surface and cell proliferation take place. By contrast, ECCD-1 mAb caused a marked decrease in TRAP $(+)$ MNC number when added during the last $3 \mathrm{~d}$, the time during which cell fusion occurs. Results are the mean \pm SEM of two experiments with four determinations for each group. * Significantly different from the group treated with $1,25 \mathrm{D}_{3}$ alone $(P<0.01)$.

quence, $H A V$. The cadherin families are known to have a common cell adhesion recognition sequence motif (-histidine-alanine-valine-, HAV) in the first extracellular domain (7). It has been reported that synthetic peptides containing the HAV sequence motif inhibit the compaction of mouse embryos and neurite outgrowth on astrocytes by antagonizing the function of the cadherins (22). We, therefore, examined whether synthetic peptides including the HAV motif sequence affected TRAP(+)MNC formation. The synthetic 17-mer peptides $\left(\mathrm{NH}_{2}-\right.$ AKYILYSHAVSSNGEAV-COOH) designed based on the sequence of the first extracellular domain of mouse E-cadherin (19) at $550 \mu \mathrm{M}$ markedly decreased TRAP $(+) \mathrm{MNC}$ formation (Fig. 6). Moreover, the synthetic 10-mer peptide $\left(\mathrm{NH}_{2}\right.$-LYSHAVSSNG-COOH) and 8 mer peptide $\left(\mathrm{NH}_{2}-\mathrm{YSHAVSSN}\right)$ at the same concentration also reduced $\operatorname{TRAP}(+) \mathrm{MNC}$ formation but to a lesser extent than did the 17-mer peptide (Fig. 6). In contrast, a synthetic control 17-mer peptide containing the same amino acids but randomly distributed $\left(\mathrm{NH}_{2}\right.$-VLHSYYASNIVEKSAGG-COOH) at $550 \mu \mathrm{M}$ had no effects on TRAP(+)MNC formation (Fig. 6).

Effects of ECCD-1 on bone resorption by TRAP(+)MNC formed in marrow cultures. Finally, we examined whether ECCD$1 \mathrm{mAbs}$ affected bone-resorbing activity of TRAP $(+)$ MNC. As shown in Fig. 7, bone marrow cells formed TRAP $(+) \mathrm{MNC}$ on sperm whale dentine slices and these cells exhibited strong resorption pit formation. ECCD-1 mAbs dramatically inhibited the formation of TRAP(+)MNC (Fig. 7, left). In parallel with this, the

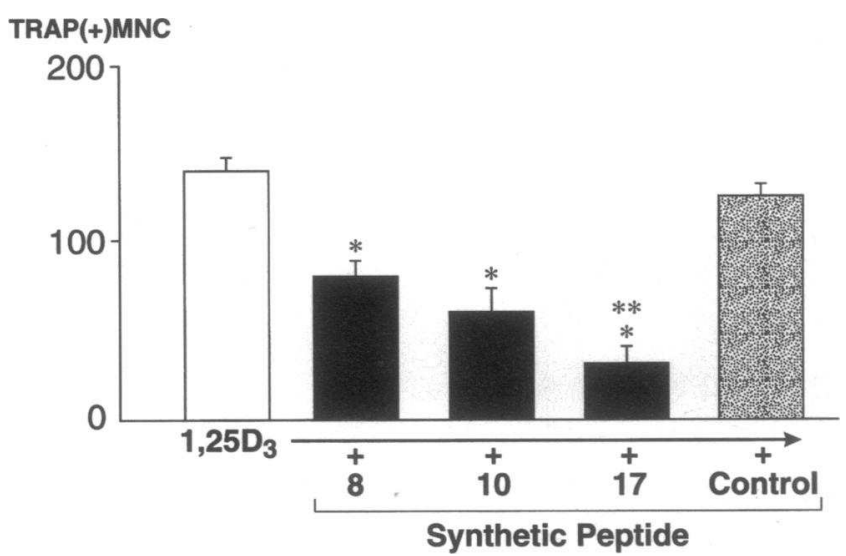

Figure 6. Effects of synthetic peptides containing cell adhesion recognition sequence on TRAP $(+)$ MNC formation. Mouse marrow cells were cultured with $10 \mathrm{nM} 1,25 \mathrm{D}_{3}$ for $6 \mathrm{~d}$ in the presence of $550 \mu \mathrm{M} \mathrm{HAV}$ containing peptides of mouse E-cadherin ( 17 mer; $\mathrm{NH}_{2}$-AKYILYSHAVSSNGEAV-COOH, $10 \mathrm{mer}$; $\mathrm{NH}_{2}$-LYSHAVSSNG-COOH and 8 mer; $\overline{\mathrm{N}} \mathrm{H}_{2}$-YSHAVSSN-COOH) or control peptides $\left(\mathrm{NH}_{2}\right.$-VLHSYYASNIVEKSAGG-COOH). HAV-containing 17-mer peptides markedly and 10- and 8-mer peptides to a lesser extent decreased TRAP(+)MNC formation, whereas control peptides did not. Results are the mean \pm SEM of three experiments with four determinations for each group. * Significantly different from the group treated with $1,25 \mathrm{D}_{3}$ alone $(P$ $<0.005)$. $* *$ Significantly different from the group treated with $8 \mathrm{mer}$ $(P<0.05)$.

antibodies also markedly decreased resorption pit formation (Fig. 7, right). Control rat IgG showed no effects. The results demonstrate that ECCD-1 mAbs decreased the formation of TRAP $(+) \mathrm{MNC}$ with bone-resorbing activity and suggest that E-cadherin expression is important for the formation of boneresorbing osteoclasts.
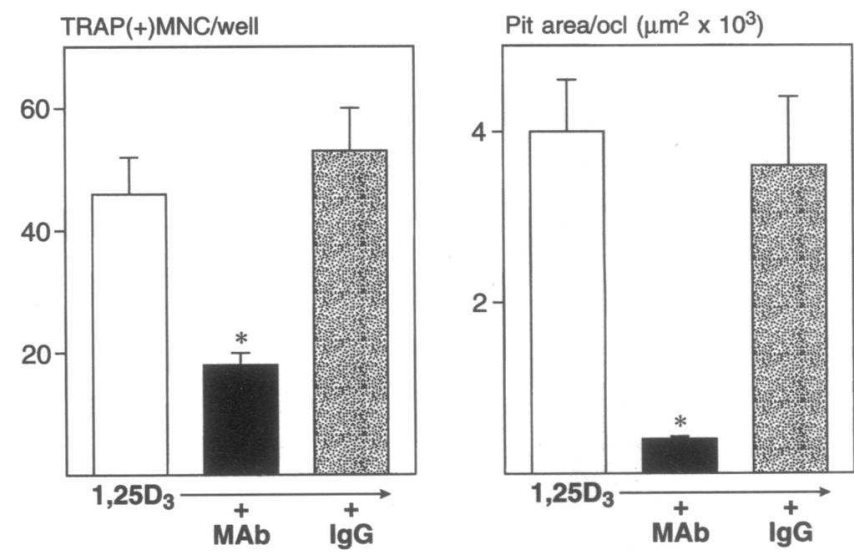

Figure 7. Effects of ECCD-1 on TRAP(+)MNC formation (left) and on bone resorption by TRAP $(+) \mathrm{MNC}($ right $)$ on dentine slices. Mouse marrow cells were cultured with $10 \mathrm{nM} 1,25 \mathrm{D}_{3}$ on dentine slices for 6 $\mathrm{d}$ in the absence or presence of ECCD-1 mAb or control rat $\operatorname{IgG}(\operatorname{IgG})$ $(10 \mu \mathrm{g} / \mathrm{ml})$. TRAP $(+) \mathrm{MNC}$ and resorption pit formation were assessed as described in Methods. The data are expressed as pit area/

TRAP(+)MNC. TRAP(+)MNC formation was decreased and consequently, resorption pit formation was inhibited by ECCD-1 mAb. Results are the mean $\pm S E M$ of two experiments with four determinations for each group. ${ }^{*}$ Significantly different from the group treated with $1,25 \mathrm{D}_{3}$ alone $(P<0.005)$. 


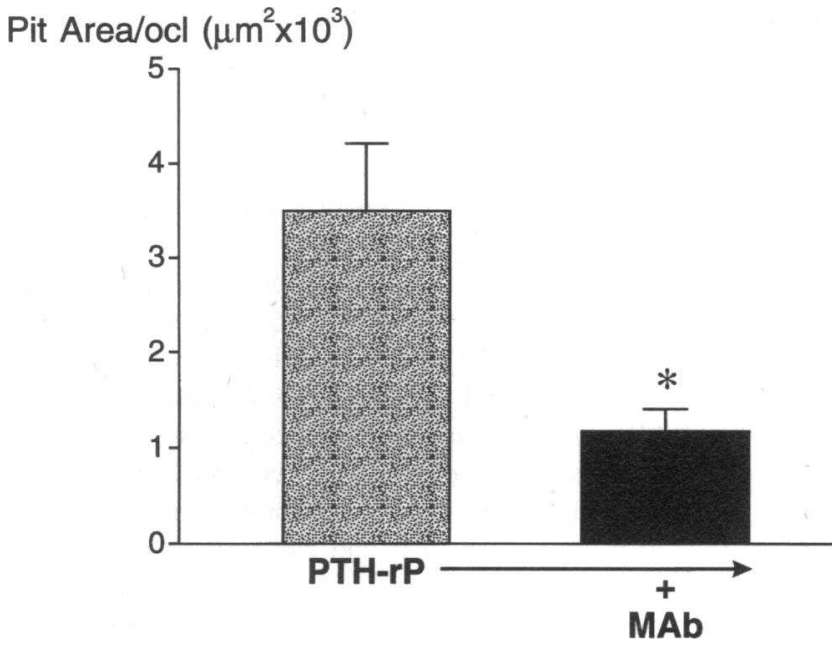

Figure 8. Effects of ECCD-1 on resorption pit formation by isolated mature mouse osteoclasts. Mature osteoclasts were isolated from the femora and tibiae of 5-d-old C57BL mice as described in the text. Osteoclasts were incubated with $50 \mathrm{ng} / \mathrm{ml}$ synthetic (1-34) human PTH$\mathrm{rP}$ for $\mathbf{2 4} \mathrm{h}$ on dentine slices in the absence or presence of the antibodies. At the end of the incubation, numbers of TRAP $(+)$ osteoclasts were counted. The data are expressed as pit area/osteoclast. The ECCD-1 $\mathrm{mAb}$ significantly inhibited resorption pit formation by mature osteoclasts. Basal pit formation without PTH-rP was $1.3 \pm 0.4 \mu \mathrm{m}^{2} \times 10^{3} /$ ocl. Results are the mean \pm SEM of two experiments with four determinations for each group. *Significantly different from the group treated with PTH-rP alone $(P<0.01)$.

Effects of ECCD-1 on resorption pit formation by isolated mature mouse osteoclasts. As shown in Fig. $2 E$, TRAP $(+)$ MNC formed after the fusion of TRAP $(+)$ mononuclear osteoclast precursors expressed comparable levels of $\mathrm{E}$ cadherin to those seen in TRAP $(+)$ mononuclear cells. This result is consistent with the in vivo immunohistochemical observation that osteoclasts intensely express E-cadherin. These results together with the data shown in Fig. 7 raise the possibility that E-cadherin may play a role in bone resorption by already formed osteoclasts. To examine the functional significance of E-cadherin expression in preexisting osteoclasts, resorption pit formation by isolated mature mouse osteoclasts treated with synthetic (1-34) human PTH-rP were assessed in the presence of the ECCD-1 mAbs. The antibodies significantly inhibited PTH-rP-stimulated resorption pit formation by mature osteoclasts (Fig. 8). In these experiments, numbers of mature osteoclasts on dentine slices in the absence or presence of the antibodies at the end of 24-h culture were not different (data not shown), indicating that the antibodies had no effects on the attachment of the osteoclasts to dentine surfaces and proliferation of the cells on dentine.

Effects of ECCD-1 and synthetic HAV-containing peptides on bone resorption in organ cultures of neonatal mouse calvariae. It has been shown that bone resorption observed in organ cultures of neonatal mouse calvariae results from the activation of preexisting osteoclasts (16). Using this assay, we have found that the ECCD-1 mAbs and synthetic 17 mer peptides of mouse E-cadherin containing HAV sequence motif inhibit bone resorption that is stimulated by $10 \mathrm{nM} 1,25 \mathrm{D}_{3}$ (Fig. 9).

\section{Discussion}

This study provides insight into the mechanism by which multinucleated osteoclasts are formed through the fusion of marrow-
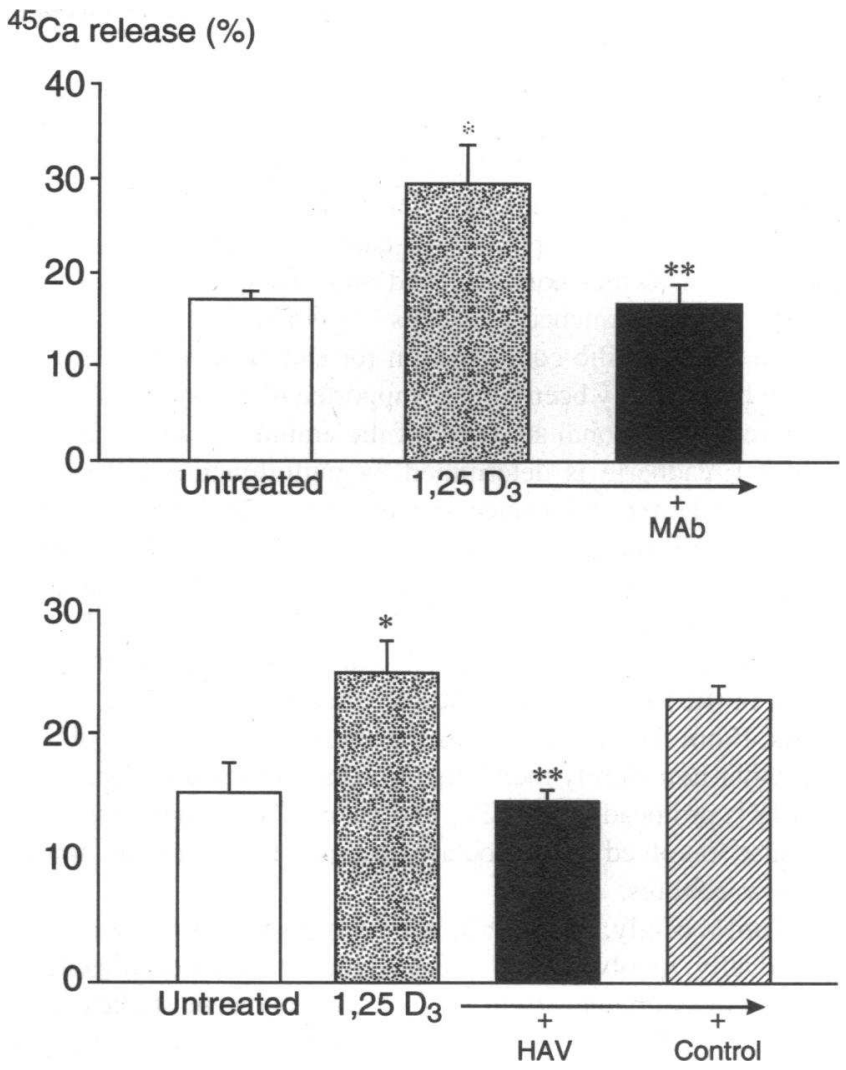

Figure 9. Effects of ECCD-1 (top) and synthetic HAV-containing peptides (bottom) on bone resorption in organ cultures of neonatal mouse calvariae. Mouse calvariae were incubated with $10 \mathrm{nM} 1,25 \mathrm{D}_{3}$ in the absence or presence of the antibodies or peptides for $72 \mathrm{~h}$. Both the antibodies (top) and the HAV-containing peptides (bottom) inhibited bone resorption, whereas control peptides did not (bottom). Results are the mean \pm SEM of two experiments with four determinations for each group. *Significantly higher than untreated bones $(P<0.01)$. ** Significantly different from bones treated with $1,25 \mathrm{D}_{3}$ alone $(P<0.01)$.

derived mononuclear precursors. Cell-cell fusion involves merging of the lipid components of the membranes of neighboring cells. Recent studies suggest that exposure of the hydrophobic domains of integral membrane proteins (called fusion proteins) due to changes in their conformation promotes the merger of membrane lipid bilayers (23). It has been proposed that cell-cell adhesion causes such conformational changes in fusion proteins (24). Evidence is accumulating that the cadherin families, which have homophilic properties, play important roles in cell-cell recognition and attachment which eventually leads to cell-cell fusion in diverse tissues and species. M-cadherin has been shown to induce terminal muscle differentiation by mediating myoblast fusion (25). N-cadherin has been implicated in cell-cell adhesion in neurite growth in various neural tissues (19) and also in myoblast fusion (4). Fusion of cytotrophoblasts to form multinucleated trophoblasts in the placenta has been found to be mediated by E-cadherin (2). Although the precise molecular mechanisms which are involved in the events which occur subsequent to cell-cell recognition and adhesion in the entire cell fusion process still need to be elucidated, our results demonstrate that E-cadherin, but not $\mathrm{N}$ - or P-cadherin, is expressed in osteoclasts in vivo and also in vitro in parallel with an increase in the fusion, resulting in an increase in TRAP $(+)$ MNC formation. Furthermore, ECCD-1 and syn- 
thetic peptides of mouse E-cadherin containing cell adhesion recognition sequence, $\mathrm{HAV}$, decreased osteoclast-like cell formation. A previous study reported by Nose et al. (8) has demonstrated that the ECCD-1 mAbs recognize the site around nonconserved amino acid residues in the amino-terminal (residues 13, 16, and 19) and indicates that neutralizing activity of the ECCD-1 is specific for mouse E-cadherin. These authors also have suggested that nonconserved amino acid residues around $-\mathrm{H}^{79}-\mathrm{A}^{80}-\mathrm{V}^{81}$ - sequence (residues 78 and/or 83 ) might determine a type-specific conformation for each cadherin (8). This notion has recently been further supported by the study in which the three dimensional structure of the amino terminal repeat of mouse E-cadherin is determined by multidimensional heteronuclear magnetic resonance spectroscopy (28). These results together with our data suggest that E-cadherin may determine osteoclast formation by initiating the fusion of the hematopoietic mononuclear osteoclast precursors in bone marrow. To our knowledge, this is the first demonstration that E-cadherin plays a role in the formation of multinucleated bone-resorbing osteoclasts. From the present results we cannot exclude a possibility that other new family members of cadherin including clones 511 (18), protocadherins (26) and desmosomal cadherins (27) are also involved in osteoclast-like cell formation in mouse marrow cultures.

Until recently, E-cadherin has been thought to be relatively specifically involved in the organization and morphogenesis of cells of epithelial origin (6). However, recent studies have reported that the expression of E-cadherin is not limited to epithelial tissues since it is also detected in non-epithelial tissues such as sensory neurons (29) and epidermal Langerhans cells which are derived from leukocytes (30). In agreement with these reports, our results have shown that E-cadherin is expressed in osteoclasts that are terminally differentiated cells of hematopoietic origin and plays an important role in the differentiation of osteoclasts by modulating the fusion of the hematopoietic mononuclear precursors. The differentiation of hematopoietic cells into osteoclasts is known to require the support of accessory cells including osteoblasts and stromal cells, which may be mediated by soluble cytokines and/or cell-cell direct contact $(1,31)$. In the latter case, CAMs such as cadherins and integrins are likely involved. In support of this notion, it has recently been reported that VCAM and integrin $\alpha_{4} \beta_{1}$ or $\alpha_{4} \beta_{7}$ may be involved in the cell-cell contact between osteoblastic stromal cells and osteoclast precursors (32). As a cadherin for osteoblasts which may also take a part in cell-cell interactions in bone marrow, OB-cadherin has recently been cloned (33). Furthermore a recent report has demonstrated a heterotypic interaction between E-cadherin on epithelium and integrin $\alpha^{\mathrm{E}} \boldsymbol{\beta}_{7}$ on parenchymal $\mathrm{T}$ lymphocytes in the small intestine (34). Thus, it seems feasible to speculate that a variety of CAMs, including cadherins and integrins, may play roles to mediate homotypic cell-cell adhesion between the hematopoietic mononuclear osteoclast precursors and heterotypic interactions between the hematopoietic osteoclast precursors and their accessory cells during the sequential events of osteoclast formation. Temporal and spatial expression of these CAMs in bone marrow cells may result in the development of functional cell-cell communication networks in the bone microenvironment. Bone may then provide an environment which allows these calcium-dependent CAMs to optimally exert their function by the release of calcium during physiological bone remodeling, which in turn might modulate bone morphogenesis.

Of interest, we have found that megakaryocytes (Fig. $1 C$ ), the precursors of platelets, and alveolar macrophages (Mbalaviele, G., and T. Yoneda, unpublished observation ) also express E-cadherin. Taken together, these findings suggest that E-cadherin plays a potentially important role in the differentiation of hematopoietic cells. They may provide new insights into our understanding of biological functions of E-cadherin in hematopoiesis.

It is noteworthy that $(a)$ immunohistochemistry of bone has shown that pre-existing mature osteoclasts express E-cadherin not only on their apical cell membranes but also along their ruffled borders, the activated parts of the osteoclast that resorb bone, $(b)$ TRAP $(+)$ MNC that are formed in culture are stained with E-cadherin antibodies, $(c)$ ECCD-1 decrease bone resorption by TRAP $(+) \mathrm{MNC}$, and $(d)$ bone resorption in cultures of isolated mature mouse osteoclasts and calvariae in organ cultures is markedly inhibited by the ECCD-1 mAbs and synthetic HAV-containing peptides. This may suggest an additional role for E-cadherin in the mature multinucleated cells as well as in their mononuclear precursors. These data are consistent with the notion that E-cadherin is implicated not only in osteoclast formation but in mature osteoclast function, and suggest a potential role for it in ruffled border formation. Complete understanding of each of the mechanisms by which E-cadherin modulates osteoclastic bone resorption awaits further studies.

The HAV motif is a conserved sequence present in the first extracellular repeat of the classical cadherins (28). The HAV motif is also conserved in influenza strain A hemagglutinins which are integral membrane proteins mediating attachment and fusion of the virus with the epithelia of the mammalian and avian upper respiratory tract (35). Monoclonal antibodies raised against this first extracellular domain inhibit cell-cell adhesion mediated by cadherin (19). Furthermore, the synthetic peptides containing the HAV sequence have been shown to inhibit compaction of eight-cell-stage mouse embryos and rat neurite outgrowth on astrocytes (22) and myoblast fusion (4), all of which are known to be mediated by cadherins. These data strongly indicate the importance of the HAV sequence for the fusion and cellular differentiation that are dependent on cadherins. In the present study, we have found that the HAV-containing synthetic peptides of mouse E-cadherin affect another cell differentiation process which involves cell-cell fusion, i.e., formation of multinucleated bone-resorbing osteoclasts. Of note, the potency of the synthetic peptides is in order of 17,10 , and 8 mer, suggesting that sequences surrounding HAV sequence are involved in modulating the effects of the peptides. Consistent with our data Nose et al. (8) has demonstrated that mutation of residues 78 ( serine) and 83 (serine) flanking $-\mathrm{H}^{79}-\mathrm{A}^{80}-\mathrm{V}^{81}$ in amino-terminal of E-cadherin to the corresponding P-cadherin amino acids affects the binding specificity of E-cadherin. Most recently, Overduin et al. (28) also has indicated that residues flanking HAV sequence provide cadherins with homophilic specificity by determination of the three-dimensional structure of the amino-terminal repeat of mouse E-cadherin by multidimensional heteronuclear magnetic resonance spectroscopy. The result, thus, further supports the notion that the cadherin, here most likely E-cadherin, plays a critical role in the fusion of hematopoietic mononuclear osteoclast precursors leading to the formation of multinucleated osteoclasts.

Finally, the HAV sequence is also found in fibroblast growth factor receptors and deletion of this region completely abolishes fibroblast growth factor receptor function (36), suggesting that the HAV sequence may be involved in elicitation of receptormediated signal transduction. It is, therefore, possible that since 
the HAV sequence inhibits osteoclast formation, the fusion of mononuclear osteoclast precursors mediated by E-cadherin may also involve cytoplasmic signaling events, as recently proposed (37).

Although we have demonstrated that osteoclasts are positively stained with mAbs to E-cadherin, it is possible that the cadherin expressed in osteoclasts has the same epitope against which the MAbs were raised, but the full sequence of the cadherin expressed in osteoclasts may not be identical to E-cadherin. In fact, using degenerative primers designed according to conserved cytoplasmic regions of $\mathrm{N}$-cadherin $(18,19)$, we have found that there are several PCR products that have either identical or homologous but different sequences to E-cadherin in mRNA of 6-day culture of mouse bone marrow cells. Thus, it is intriguing to speculate that osteoclasts in bone may express not only E-cadherin but also a unique class of cadherins that have sufficient sequence homology to E-cadherin to be positively stained with the mAbs to E-cadherin as we have shown. Using the same degenerative primers as ours, Suzuki et al. (18) and Sano et al. (26) have cloned new members of cadherin which are called clones 5 to 11 in rat brain and retina cDNA and protocadherins in a human brain cDNA library, respectively. We have not yet finished sequencing all of the PCR products and do not know whether mouse homologues of these new cadherin family members are expressed in hemopoietic osteoclast precursors in mouse bone marrow. It is also unknown at the present time whether the mAbs to E-cadherin and HAVcontaining synthetic peptides used in the present study block these new cadherins. These issues remain to be investigated.

\section{Acknowledgments}

We are grateful to Dr. Kemler for the generous gift of DECMA-1 mAb and to $\mathrm{M}$. Dallas for image analysis. We are also grateful to T. Barrios and N. Garrett for their expert secretarial assistance.

This work was supported in part by grants AR-39529 and AR-28149 from the National Institutes of Health.

\section{References}

1. Mundy, G. R., and G. D. Roodman. 1987. Osteoclast ontogeny and function. In Bone and Mineral Research. W. A. Peck, editor. Elsevier, Amsterdam. 209 280.

2. Coutifaris, C., L.-C. Kao, H. M. Sehdev, U. Chin, G. O. Babalola, O. W. Blaschuk, and J. F. Strauss. 1991. E-cadherin expression during the differentiation of human trophoblasts. Development (Camb.). 113:767-777.

3. Kliman, H. J., J. E. Nestler, E. Sermasi, J. M. Sanger, and J. F. Strauss 1986. Purification, characterization and in vitro differentiation of cytotrophoblasts from human term placenta. Endocrinology. 118:1567-1582.

4. Mege, R. M., D. Goudou, C. Diaz, M. Nicolet, L. Garcia, G. Geraud, and R. Rieger. 1992. N-cadherin and N-CAM in myoblast fusion: compared localization and effect of blockadge by peptides and antibodies. J. Cell. Sci. 103:897906.

5. Hasty, P., A. Bradley, J. H. Morris, D. G. Edmondson, J. M. Venuti, E. N. Olson, and W. H. Klein. 1993. Muscle deficiency and neonatal death in mice with a targeted mutation in the myogenic gene. Nature (Lond.). 364:501-506.

6. Takeichi, M. 1991. Cadherin cell adhesion receptors as a morphogenetic regulator. Science (Wash. DC). 251:1451-1455

7. Grunwald, G. B. 1993. The structural and functional analysis of cadherin calcium-dependent cell adhesion molecules. Curr. Opin. Cell Biol. 5:797-805.

8. Nose, A., K. Tsuji, and M. Takeichi. 1990. Localization of specificity determining sites in cadherin cell adhesions molecules. Cell. 61:147-155.

9. Vestweber, D., and R. Kemler. 1985. Identification of a putative cell adhesion domain of uvomorulin. EMBO (Eur. Mol. Biol. Organ.) J. 4:3393-3398.

10. Yoneda, T., M. Niewolna, C. Lowe, E. Izbicka, and G. R. Mundy. 1993. Hormonal regulation of $\mathrm{pp} 60^{\mathrm{c}-\mathrm{scc}}$ expression during osteoclast formation in vitro. Mol. Endocrinol. 7:1313-1318.

11. Wijngaert, F. B., and E. H. Burger. 1986. Demonstration of tartrate- resistant acid phosphatase in undecalcified, glycomethacrylate-embedded mouse bone: a possible marker for (pre) osteoclast identification. J. Histo. Cytol. 34:1317-1323.

12. Oreffo, R. O. C., G. R. Mundy, S. Seyedin, and L. Bonewald. 1989. Activation of the bone derived latent TGF beta complex by isolated osteoclasts. Biochem. Biophys. Res. Commun. 158:817-823.

13. Oreffo, R. O. C., L. F. Bonewald, A. Kukita, I. R. Garrett, S. M. Seyedin, D. Rosen, and G. R. Mundy. 1990. Inhibitory effects of the bone-derived growth factors osteoinductive factor and transforming growth factor- $\beta$ on isolated osteoclasts. Endocrinology. 126:3069-3075.

14. Yoneda, T., C. Lowe, C. H. Lee, G. Gutierrez, E. Izbicka, M. Niewolna, P. J. Williams, and G. R. Mundy. 1993. Herbimycin A, a pp60 ${ }^{\mathrm{c}-\mathrm{sec}}$ tyrosine kinase inhibitor, inhibits osteoclastic bone resorption in vitro and hypercalcemia in vivo. J. Clin. Invest. 91:2791-2795.

15. Boyde, A., N. N. Ali, and S. I. Jones. 1984. Resorption of dentine by isolated osteoclasts in vitro. Br. Dent. J. 156:216-220.

16. Garrett, I. R., and G. R. Mundy. 1989. Relationship between interleukin1 and prostaglandins in resorbing neonatal calvaria. J. Bone Miner. Res. 4:789794.

17. Boyce, B. F., H. Chen, P. Soriano, and G. R. Mundy. 1993. Histomorphometric and immunocytochemical studies of src-related osteopetrosis. Bone. 14:335-340.

18. Suzuki, S., K. Sano, and H. Tanihara. 1991. Diversity of the cadherin family: evidence for eight new cadherins in nervous tissue. Cell Reg. 2:261-270.

19. Miyatani, S., K. Shimamura, M. Hatta, A. Nagafuchi, A. Nose, M. Matsunaga, K. Hatta, and M. TAkiechi. 1989. Neural cadherin: role in selective cell-cell adhesion. Science (Wash. DC). 245:631-635.

20. Sanger, F., S. Nicklen, and A. R. Coulson. 1977. DNA sequencing with chain-terminating inhibitors. Proc. Natl. Acad. Sci. USA. 74:5463-5467.

21. Takahashi, N., H. Yamana, S. Yoshi, G. D. Roodman, G. R. Mundy, S. J. Jones, A. Boyde, and T. Suda. 1988a. Osteoclast-like cell formation and its regulation by osteotropic hormones in mouse bone marrow cultures. Endocrinology. 122:1373-1382.

22. Blaschuk, O. W., S. Robert, S. David, and Y. Pouliot. 1990a. Identification of a cadherin cell adhesion recognition sequence. Dev. Biol. 139:227-229.

23. White, J. M. 1992. Membrane fusion Science (Wash. DC). 258:917-924.

24. Blobel, C. P., T. G. Wolfsberg, C. W. Turck, D. G. Myles, P. Primakoff, and J. M. White. 1992. A potential fusion peptide and an integrin ligand domain in a protein active in sperm-egg fusion. Nature (Lond.). 356:248-251.

25. Donalies, M., M. Cramer, M. Ringwald, and A. Strazinski-Powitz. 1991. Expression of M-cadherin, a member of the cadherin multigene family, correlates with differentiation of skeletal muscle cells. Proc. Natl. Acad. Sci. USA. 88:8024 8028.

26. Sano, K., H. Tanihara, R. L. Heimark, S. Obata, M. Davidson, T. St. John, S. Taketani, and S. Suzuki. 1993. Protocadherins: a large family of cadherinrelated molecules in central nervous system. EMBO (Eur. Mol. Biol. Organ.) J. 12:2249-2256.

27. Koch, P. J., and W. W. Franke. 1994. Desmosomal cadherins: another growing multigene family of adhesion molecules. Curr. Opin. Cell Biol. 6:682687.

28. Overduin, M., T. S. Harvey, S. Bagby, K. I. Tong, P. Yau, M. Takeichi, M. Ikura. 1995. Solution structure of the epithelial cadherin domain responsible for selective cell adhesion. Science (Wash. DC). 267:386-389.

29. Shimamura, K. H. Takahashi, and M. Takeichi. 1992. E-cadherin expression in a particular subset of sensory neurons. Dev. Biol. 152:242-254.

30. Tang, A., M. Amagai, L. G. Granger, J. R. Stanley, and M. C. Udey. 1993. Adhesion of epidermal Langerhans cells to keratinocytes mediated by Ecadherin. Nature (Lond.). 361:82-85.

31. Takahashi, N., T. A. Akatsu, N. Udagawa, T. Sasaki, A. Yamaguchi, J. M. Moseley, T. J. Martin, and T. Suda. 1988b. Osteoblastic cells are involved in osteoclast formation. Endocrinology. 123:2600-2602.

32. Duong, L. T., H. Tanaka, and G. A.'Rodan. 1994. VCAM-1 involvement in osteoblast-osteoclast interaction during osteoclast differentiation. J. Bone Miner. Res. 9(Suppl 1):S131.

33. Okazaki, M., S. Takeshita, S. Kawai, R. Kikuno, A. Tsujimura, A. Kudo, and E. Aman. 1994. Molecular cloning and characterization of OB-cadherin, a new member of cadherin family expressed in osteoblasts. J. Biol. Chem. 269:12092-12098.

34. Cepek, K. L., S. K. Shaw, C. M. Parker, G. J. Russell, J. S. Marrow, D. L. Rimm, and M. B. Brenner. 1994. Adhesion between epithelial cells and T lymphocytes mediated by E-cadherin and the $\alpha^{\mathrm{E}} \beta_{7}$ integrin. Nature (Lond.). 372:190-193.

35. Blaschuk, O. W., Y. Pouliot, and P. C. Holland. 1990b. Identification of a conserved region common to cadherins and influenza strain $\mathrm{A}$ hemagglutinins. J. Mol. Biol. 211:679-682.

36. Byers, S., E. Amaya, S. Munro, and O. Blaschuk. 1992. Fibroblast growth factor receptors contain a conserved HAV region common to cadherins and infleunza strain A hemagglutinins: a role in protein-protein interactions? Dev. Biol. 152:411-414.

37. Cowin, P. 1994. Unraveling the cytoplasmic interactions of the cadherin superfamily. Proc. Natl. Acad. USA. 91:10759-10761. 